\title{
Effects of Latinx Parental English Proficiency on Stress
}

Maria Alvarez Pineda

Dominican University of California

\section{Introduction}

In the US, patients who have Limited English Proficiency (LEP) report having more problems communicating with their children's doctor (Wilson et al., 2005) which leads to these children having worse health care access than those who have parents with a High English Proficiency (HEP; Eneriz-Wiemer et al. 2014).

Parents with LEP experience discrimination in this setting which can lead to increased psychological distress (Torres et al 2012).

Gender, place of birth, age, years lived in the U.S, marital status, education, employment, language spoken at home, and perceived discrimination are important confounders for a Latinx parent when it comes to their child's healthcare (Torres et al. 2012, Stevenson et al., 2017).

\section{Hypotheses:}

Parents with LEP will:

- experience higher stress levels after they are informed they are participating in an interview about their experiences taking their children to the

- experience higher stress levels after being interviewed

- feel more discriminated against in a medical setting

than parents with HEP.

Method
$\begin{aligned} & \text { This mixed methods study had a } \\ & \text { total of } 22 \text { Latinx parents. }\end{aligned}$
$\begin{aligned} & \text { Participant's ages ranged from } \\ & 19 \text { to } 70(\mathrm{M}=43.4, \mathrm{SD}=12.2) .\end{aligned}$
$\begin{aligned} & \text { The sample consisted of } 20 \\ & \text { Pre-test }\end{aligned}$
women and 2 men. The study
followed the order to the right.

\section{Measures}

Language Fluency Measure (Kim \& Chao, 2009) measuring participants English proficiency 3-items and a 5-point scale.

Everyday Discrimination Scale-Adapted (Gonzalez et al., 2016) is a 9-question scale that uses a 4-point scale to measure discrimination in a specific setting, a health care setting.

Acute Stress Appraisals (Mendes et al., 2007) consists of a pre- and post-test that measures stress before and after participating in a stressful task, an interview this case.

Interview in-person or over the phone to further understand the participants experiences and feelings when taking their children to the doctor.

\section{Results}

Quantitative

In trying to find a relationship between stress levels, discrimination and English language proficiency four covariates were accounted for: participant's age, years living in the US, education level, and number of children.

No statistical significance was found between the association of English language proficiency with stress from the interviews and discrimination $(p>0.05)$.

The Acute Stress pre- and post-tests were positively correlated to each other $(r=0.469, p=0.028)$
Linear Regression Table, $N=22$

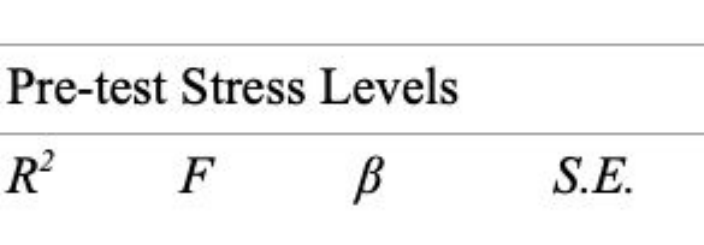 0.3591 .792

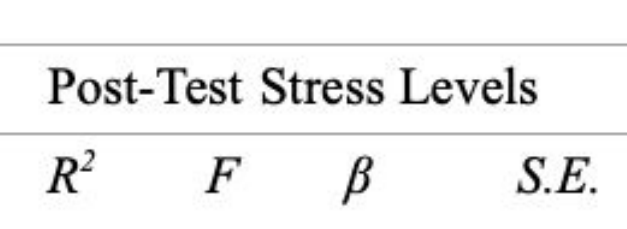 0.0610 .20

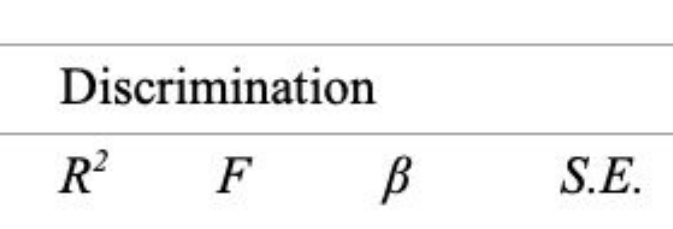 Age $0.003 \quad 0.229$ 0.207 0.1950 .774 Years in Us

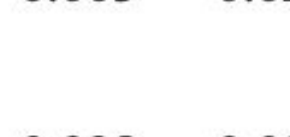 $\begin{array}{lll}0.008 & 0.027\end{array}$

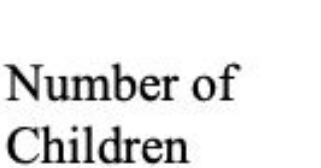 $0.038 \quad 0.036$ $-0.0060 .035$ $\begin{array}{lll}0.18 & 0.144\end{array}$$$
-0.067 \quad 0.14
$$$$
0.1670 .202
$$$$
0.024 \quad 0.138
$$$$
0.363 \quad 0.236
$$$$
0.024 \quad 0.13
$$$$
\text { Language Fluency }
$$$$
0.1220 .225
$$

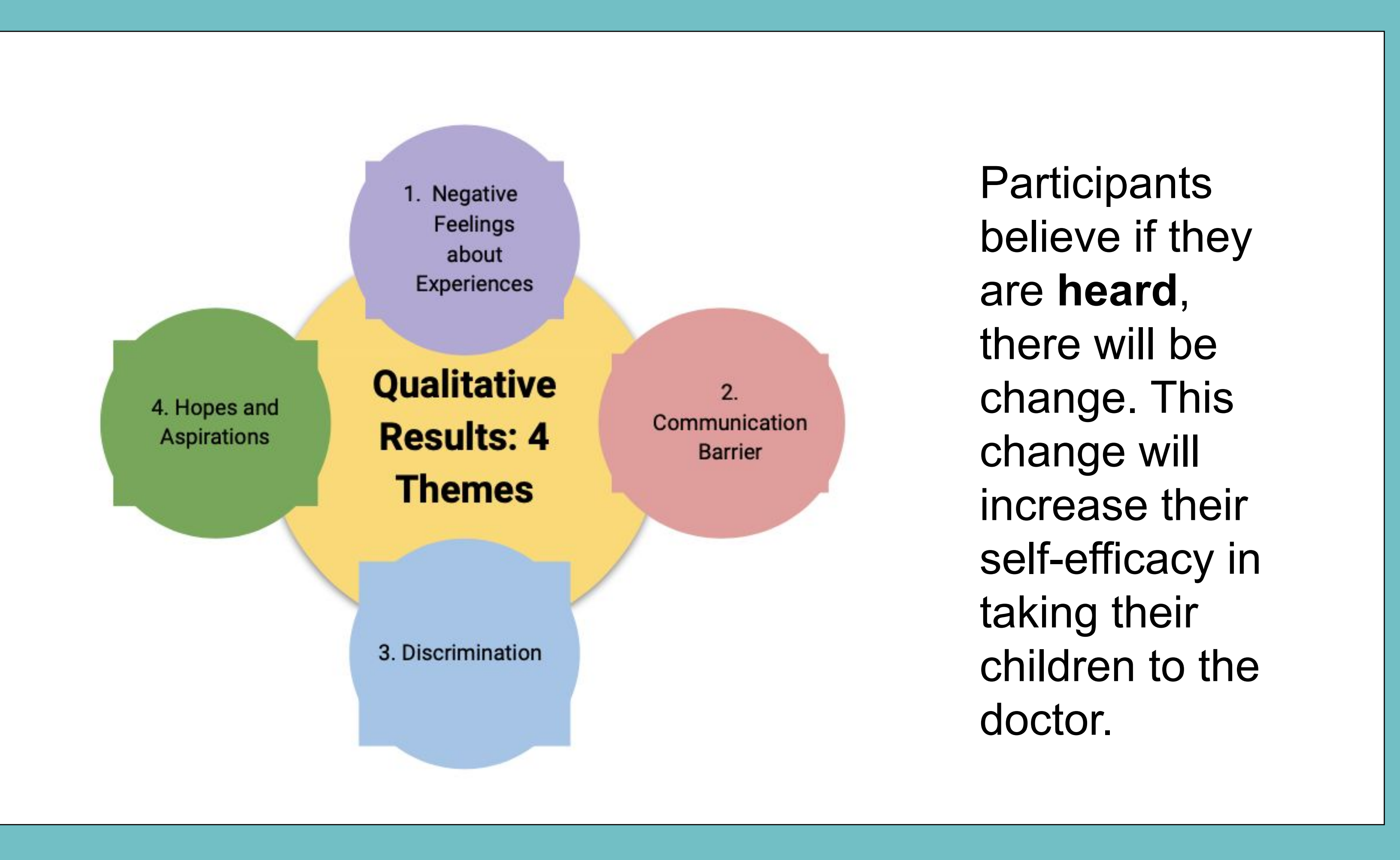

\section{Discussion}

The goal of this study was to understand if English fluency is a factor associated to stress and discrimination Latinx parents face when taking their children to the doctor. There were no significan quantitative results found. However, in the interview

communication barrier was a significant theme which supports previous research about communication barrier preventing parents from taking their children to the doctor (Flores et al. 2005; Yu et al., 2006).

The results also showed that parents who speak English as a second language face more discrimination than parents who speak English as their first language (Rios-Salas \& Larson, 2015 Wilson et al., 2005).

Limitations:

- Small sample size

- Self-report

- Participants predominantly Mexican

Future Directions:

- A larger study should be conducted including more ethnic and diverse backgrounds.

- A study using the hopes and aspirations participants discussed as interventions should be conducted. 